Article

\title{
Evaluation of Irradiation Hardening of P92 Steel under Ar Ion Irradiation
}

\author{
Qingshan $\mathrm{Li}^{1}{ }^{1}$, Yinzhong Shen ${ }^{1}{ }^{*}$, Jun Zhu ${ }^{2}, \mathrm{Xi}_{\text {Huang }}{ }^{1}$ and Zhongxia Shang ${ }^{3}$ \\ 1 School of Mechanical Engineering, Shanghai Jiao Tong University, No. 800 Dongchuan Road, \\ Shanghai 200240, China; liqingshan999@163.com (Q.L.); huangxi060231@126.com (X.H.) \\ 2 Jiangsu Nuclear Power Co., Ltd., CNNP, No. 28 Haitang Mid-Road, Lianyungang 222042, China; \\ zhujun0345@126.com \\ 3 School of Materials Science and Engineering, Shanghai Jiao Tong University, 800 Dongchuan Road, \\ Shanghai 200240, China; shangzx_568@126.com \\ * Correspondence: shenyz@sjtu.edu.cn; Tel.: +86-21-3420-7117
}

Received: 25 December 2017; Accepted: 25 January 2018; Published: 27 January 2018

\begin{abstract}
P92 steel was irradiated with Ar ion up to $10 \mathrm{dpa}$ at 200,400 , and $700{ }^{\circ} \mathrm{C}$. The effect of $\mathrm{Ar}$ ion irradiation on hardness was investigated with nanoindentation tests and microstructure analyses. It was observed that irradiation-induced hardening occurred in the steel after Ar ion irradiation at all three temperatures to $10 \mathrm{dpa}$. The steel exhibited significant hardening at 200 and $700{ }^{\circ} \mathrm{C}$, and slight hardening at $400{ }^{\circ} \mathrm{C}$ under Ar ion irradiation. Difference in the magnitude of irradiation-induced hardening at different temperature in the steel is attributed to different changes in the microstructure of the steel that arose from the irradiation. Irradiation-induced hardening in the P92 steel irradiated at $200{ }^{\circ} \mathrm{C}$ is attributed to the occurrence of both dislocation loops and other fine irradiation defects during irradiation. Slight hardening in the steel irradiated at $400{ }^{\circ} \mathrm{C}$ mainly arises from the annihilation of defect clusters at this temperature. The occurrence of fine Ar bubbles with high number density during the Ar ion irradiation at $700{ }^{\circ} \mathrm{C}$ resulted in the significant hardening in the steel.
\end{abstract}

Keywords: ferritic steel; irradiation; nanoindentation; hardness; transmission electron microscopy (TEM); microstructure

\section{Introduction}

High chromium ferritic/martensitic (F/M) steels have been considered as candidate materials for the structural components in Generation IV nuclear reactors-such as gas-cooled fast reactor (GFR), lead-cooled reactor (LFR), sodium-cooled fast reactor (SFR), and super critical water-cooled reactor (SCWR) - due to their good swelling resistance, excellent thermal properties, and low thermal expansion [1-3]. However, these components will be subjected to extreme conditions such as higher temperatures, higher neutron doses, and extremely corrosive environment, which are beyond the experience of the current reactors [3]. Irradiation damage can lead to a series of changes in microstructure, probably giving rise to a hardening of structural materials. Irradiation-induced hardening results in the degradation of fracture properties, such as ductile-to-brittle transition temperature (DBTT) shift, at low irradiation temperature [4-7]. Therefore, it is necessary to investigate the influence of irradiation on the microstructure and mechanical properties of high chromium F/M steels.

Ion irradiation technique has been recognized as a means to simulate neutron damage due to many advantages in investigating the irradiation effects on the mechanical properties of reactor structural materials, such as high damage rate, little or no residual radioactivity, and a lower cost. Additionally, irradiation conditions can be easily controlled [7,8]. A large number of studies have reported the 
mechanical properties of F/M steels after irradiation with neutrons [6], Ne ions [9], Kr ions [10,11], $\mathrm{H}$ ions, $\mathrm{He}$ ions, and electron beams [12,13]. Inert gas, especially $\mathrm{He}$, created by nuclear reaction has a significant influence on the microstructural evolution of structural materials exposed to neutrons in nuclear reactors. Although simulations recently indicated bubble formation and loss of structural integrity induced by Ar ion and Xe ion were much less compared to the case of He ion in bcc Fe [14], inert gas is still widely applied to ion irradiation experiments. Therefore, in the present work, the Ar ion was selected to create similar irradiation damage as He created in reactors. Irradiation damage depth is limited up to a few microns, so nanoindentation testing combined with ion irradiation is usually applied to investigate the influence of irradiation conditions on irradiation-induced hardening of structural materials for reactors [15-17].

Attributed to solution strengthening by $\mathrm{W}$ and Mo additions and precipitation strengthening by $\mathrm{V}$ and $\mathrm{Nb}$ additions on the basis of P91 steel, P92 steel exhibits excellent high temperature mechanical properties, which makes it a promising candidate material for in-core applications in sodium fast reactor (SFR) and fusion systems [11,18]. The irradiation response of P92 steel has received much attention in the past few years [10,11,19-22]. Most research focused on the microstructural evolution of P92 steel irradiated with $\mathrm{Kr}$ ions at 200 and $400{ }^{\circ} \mathrm{C}$ [10,11]; with Ar ions at room temperature, 290,390 , and $550{ }^{\circ} \mathrm{C}[19,20]$; and with protons at $500{ }^{\circ} \mathrm{C}$ [21]. When F/M steels are used as fuel cladding in a fast reactor, the operating temperature is expected to approach $650-700{ }^{\circ} \mathrm{C}$ [18]. Although microstructural evolution in P92 steel during irradiation has been investigated systematically in their previous work, there is a lack of available data associated with the mechanical properties of irradiated P92 steel. In addition, there appears to be few previous reports of hardening behavior in $\mathrm{F} / \mathrm{M}$ steels under ion irradiation at high temperatures (especially higher than $600{ }^{\circ} \mathrm{C}$ ). In this paper, irradiation-induced change in the hardness of P92 steel was evaluated through Ar ion irradiation at 200,400 , and $700{ }^{\circ} \mathrm{C}$ to $10 \mathrm{dpa}$ in combination with nanoindentation tests and microstructure analyses. The mechanism of irradiation-induced hardening in P92 steel under Ar ion irradiation at different irradiation temperatures to $10 \mathrm{dpa}$ was also discussed.

\section{Materials and Methods}

The initial material used in this study was commercial P92 steel. The chemical composition of the P92 steel is showed in Table 1. The P92 steel was normalized at $1050^{\circ} \mathrm{C}$ for $30 \mathrm{~min}$ then cooled by air, and then tempered at $765^{\circ} \mathrm{C}$ for $60 \mathrm{~min}$ followed by air cooling. The normalized and tempered plate was cut into specimens of $20 \mathrm{~mm} \times 6 \mathrm{~mm} \times 1 \mathrm{~mm}$ with spark erosion, then ground and polished to a mirror finish. Irradiation experiment was carried out on an implantation facility (Institute of Modern Physics of the Chinese Academy of Sciences, Lanzhou, China) using $250 \mathrm{keV} \mathrm{Ar}{ }^{2+}$ ions at 200, 400, and $700{ }^{\circ} \mathrm{C}$ under high vacuum less than $1 \times 10^{-4} \mathrm{~Pa}$. Polished samples were irradiated up to $10 \mathrm{dpa}$ and the dose rate of Ar ion irradiation was about $1.56 \mathrm{dpa} / \mathrm{h}$ for P92 steel samples. During irradiation experimentation, two small pieces were taken to suppress the samples to prevent the samples from falling from the sample plate. Correspondingly, the irradiated and unirradiated regions were acquired due to the suppressed regions not being irradiated by Ar ions. The irradiation temperature of sample was controlled using thermocouples with a fluctuation within $\pm 5^{\circ} \mathrm{C}$. The distribution of the damage level and the implanted Ar ions in the irradiated samples after irradiation were simulated through the Stopping and Range of Ions in Matter (SRIM) output vacancy file with quick Kinchin and Pease method [23], as shown in Figure 1. Depth profile of the irradiation damage has a peak at a depth of about $100 \mathrm{~nm}$.

Table 1. Chemical composition of P92 steel (in wt \%).

\begin{tabular}{cccccccccccc}
\hline $\mathbf{C}$ & $\mathbf{S i}$ & $\mathbf{C r}$ & $\mathbf{M n}$ & $\mathbf{W}$ & $\mathbf{M o}$ & $\mathbf{N b}$ & $\mathbf{N i}$ & $\mathbf{V}$ & $\mathbf{N}$ & $\mathbf{B}$ & $\mathbf{F e}$ \\
\hline 0.093 & 0.14 & 8.75 & 0.41 & 1.62 & 0.505 & 0.052 & 0.207 & 0.183 & 0.063 & 0.003 & Bal. \\
\hline
\end{tabular}




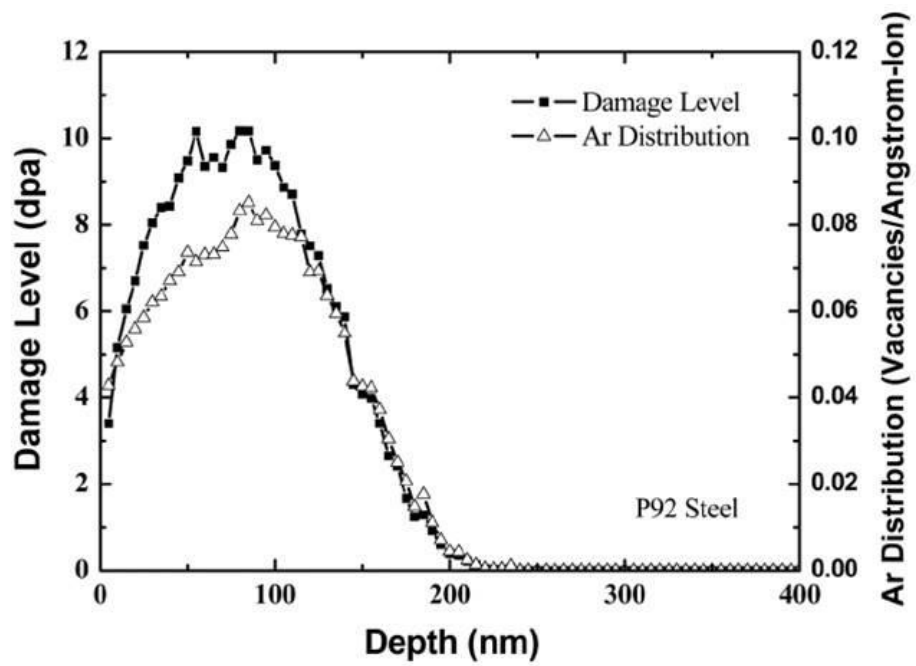

Figure 1. The depth profiles of displacement damage and Ar ions distribution in irradiated P92 steel simulated by the Stopping and Range of Ions in Matter (SRIM).

Nanoindentation hardness was measured by a MTS Nano Indenter equipped with a Berkovich type indentation tip (MTS Cooperation, Nano Instruments Innovation Center, TN, USA). The calibration of the bluntness of the indentation tip is based on the Oliver-Pharr method [24]. The hardness as a function of indenter depth was acquired by the continuous stiffness measurement (CSM) method. In order to obtain reliable results, more than six measurements were carried out for each irradiation condition.

Thin-foil TEM (transmission electron microscope, JEOL Ltd., Tokyo, Japan) specimens with a diameter of $3 \mathrm{~mm}$ were prepared from the unirradiated side of the irradiated steel samples by grinding and thinning process, and then followed by an ion milling in Gatan-691 precision ion polishing system. The thin-foil specimens were examined in a JEOL-2100 TEM at $200 \mathrm{kV}$.

\section{Results}

Figure 2 presents the average hardness of the P92 steel before and after Ar ion irradiation at 200,400 , and $700{ }^{\circ} \mathrm{C}$ to $10 \mathrm{dpa}$. For all sheet samples, the phenomenon that hardness decreases with indent depth increasing was observed at indentation depth larger than $100 \mathrm{~nm}$, which was caused by the indentation size effect (ISE) [25]. Conversely, a reverse ISE that hardness increases with depth increasing close to surface. It is clearly noted that irradiation-induced hardening was revealed for all irradiated samples. The difference in magnitudes of irradiation-induced hardening at different temperatures were shown in Figure $3, \Delta H=H_{\text {irr }}-H_{\text {uni }}$, where $\Delta H$ is defined as variable quantity of hardness after Ar ion irradiation, $H_{\text {irr }}$ is the hardness after Ar ions irradiation and $H_{\text {uni }}$ is the corresponding original hardness at the same depth. Commonly, the hardness data near the surface is not adapted to investigate the irradiation-induced hardening due to testing artifacts [26]. Besides, there are some challenges for the measurement of mechanical properties of ion implanted layers, including indentation size effect, pile-up effect, sink-in effect, and residual stresses. The pile-up and sink-in effect can be revised by scanning electron microscope (SEM) on the residual indents [27]. Many methods have been developed to estimate surface residual stress [28-30]. Compared with the hardness of the unirradiated region, the hardness of regions irradiated with Ar ion irradiation at 200 and $700{ }^{\circ} \mathrm{C}$ to $10 \mathrm{dpa}$ increased to about 1 and $1.5 \mathrm{GPa}$, respectively. The hardness after Ar ions irradiation at $400{ }^{\circ} \mathrm{C}$ was slightly higher than the unirradiated region. The most severe irradiation-induced hardening was observed at $700{ }^{\circ} \mathrm{C}$, while slight irradiation-induced hardening behavior was found at $400{ }^{\circ} \mathrm{C}$. 

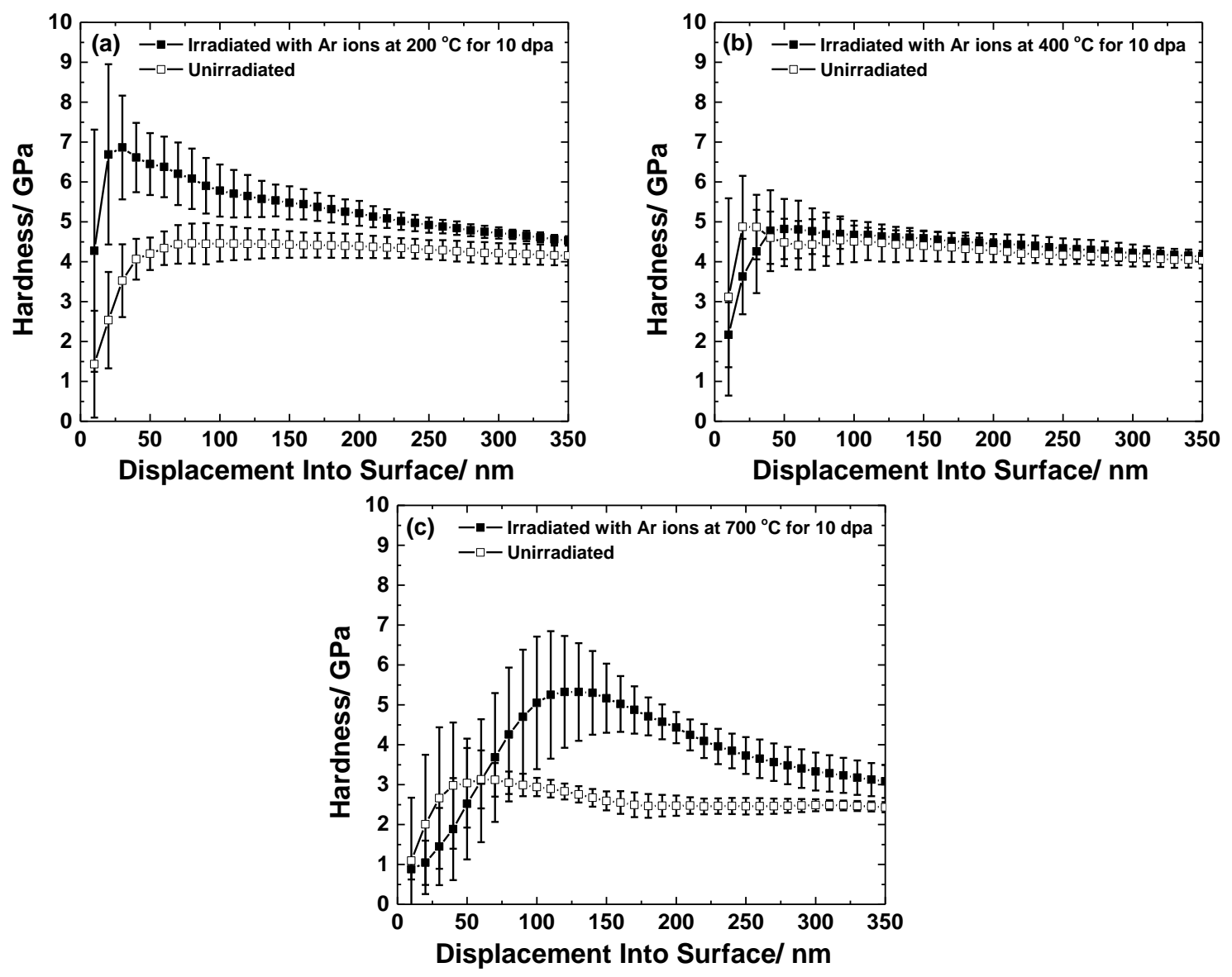

Figure 2. Indentation depth dependence of averaged nanoindentation hardness of $\mathrm{P} 92$ steel before and after Ar ion irradiation to $10 \mathrm{dpa}$ at (a) $200{ }^{\circ} \mathrm{C}$, (b) $400{ }^{\circ} \mathrm{C}$, and (c) $700{ }^{\circ} \mathrm{C}$.

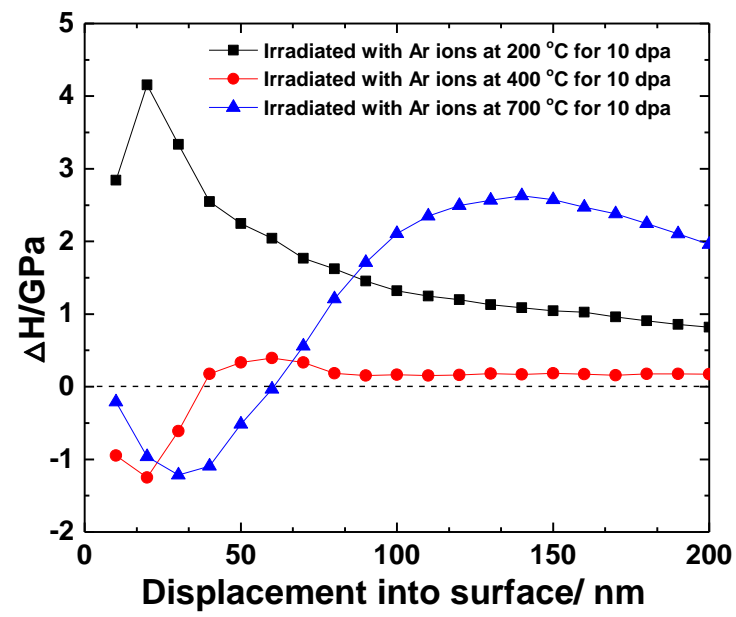

Figure 3. Indentation depth dependence of averaged nanoindentatiion hardness variation of P92 steel after Ar ion irradiation to $10 \mathrm{dpa}$ at 200,400 , and $700{ }^{\circ} \mathrm{C}$.

\section{Discussion}

In recent years, many studies on the irradiation hardening behavior of $\mathrm{F} / \mathrm{M}$ steel have been done through tensile, Vickers hardness, or nanoindentation tests [26,31-34]. Significant hardening was observed in HCM12A and T91 steels after irradiation with $2.0 \mathrm{MeV}$ protons at $400{ }^{\circ} \mathrm{C}$, while both steels irradiated at $500{ }^{\circ} \mathrm{C}$ showed a slight increase in their hardness [31]. Kimura et al. [32] 
compared the yield stress increment of $9 \mathrm{Cr}-2 \mathrm{~W}$ F/M steel before and after irradiation in Fast Flux Test Facility (FFTF)/Materials Open Test Assembly (MOTA) and found the largest irradiation hardening was observed at $373{ }^{\circ} \mathrm{C}(646 \mathrm{~K})$ at $10-15 \mathrm{dpa}$, while softening was observed in the steel specimens irradiated at temperatures above $430{ }^{\circ} \mathrm{C}(703 \mathrm{~K})$ to doses of 40 and $59 \mathrm{dpa}$. Xin et al. [33] found that irradiation-induced hardening was confirmed in CLAM steel irradiated with $140 \mathrm{keV}$ He ions with fluences up to $1 \times 10^{16} / \mathrm{cm}^{2}$ at 27,200 , and $400{ }^{\circ} \mathrm{C}$. Their results indicated that CLAM steel exhibited significant hardening at $200{ }^{\circ} \mathrm{C}$ and hardening effect decreased at $400{ }^{\circ} \mathrm{C}$, nevertheless, negligible hardening was observed when irradiation temperature was increased up to $600{ }^{\circ} \mathrm{C}$. However, there are few reports of significant irradiation-induced hardening in high chromium $\mathrm{F} / \mathrm{M}$ steels at a high irradiation temperature of $700{ }^{\circ} \mathrm{C}$. Besides, slightly irradiation-induced hardening at $400{ }^{\circ} \mathrm{C}$ observed in this work is another concern.

Figure 4 presents the TEM micrographs of the unirradiated and irradiated P92 steel taken from thin-foil samples. As shown in Figure 4a, clear martensite lath structure and high density of dislocations and precipitates were observed in the unirradiated P92 steel sample. Figure $4 \mathrm{~b}-\mathrm{e}$ illustrates the microstructural evolution of the P92 steel irradiated at 200,400 , and $700{ }^{\circ} \mathrm{C}$ to $10 \mathrm{dpa}$, suggesting that the micrographs of the irradiated samples were quite different from those of the unirradiated samples. Dislocation loops were observed in all irradiated samples, as indicated with dashed circles in Figure $4 \mathrm{~b}-\mathrm{d}$. The average diameter and the density of dislocation loops were investigated statistically in different regions of the irradiated samples. The diameter of dislocation loops in the steel samples irradiated to $10 \mathrm{dpa}$ at 200,400 , and $700{ }^{\circ} \mathrm{C}$ were determined by measuring the diameters of 271 , 226, and 187 dislocation loops respectively from more than 25 TEM images using $\mathbf{g}=\{200\}$ for each irradiated sample. The dislocation loops density was estimated by $n / V$, which was used to calculate bubbles density [35], where $n$ is the amount of dislocation loops, and $V$ is the volume of the selected regions which was estimated with a thin-foil thickness of about $50 \mathrm{~nm}$. For the samples irradiated at 200,400 , and $700{ }^{\circ} \mathrm{C}$, the average dislocation loops diameter was determined to be about 7,13 , and $17 \mathrm{~nm}$, and the number density of dislocation loops was calculated to be about $2.43 \times 10^{21}, 1.83 \times 10^{21}$, and $1.15 \times 10^{21} \mathrm{~m}^{-3}$, respectively. These results indicated that the size of dislocation loops increased, on the contrary, the density of dislocation loops decreased with the increase of irradiation temperature from 200 to $700{ }^{\circ} \mathrm{C}$. In addition, fine bubbles were observed to homogeneously distribute in the sample irradiated at $700{ }^{\circ} \mathrm{C}$, as showed in Figure $4 \mathrm{e}$. These bubbles have an average diameter of about $3 \mathrm{~nm}$ and a very high number density of about $1.87 \times 10^{25} \mathrm{~m}^{-3}[36]$.

Irradiation-induced hardening is a consequence of interactions of dislocations with irradiationinduced defects including point defects, vacancy and interstitial clusters, dislocation loops and lines, voids and bubbles, and precipitates [37]. The theories of irradiation hardening are based on the assumption that these irradiation defects can act as obstacles to the glide of dislocations and different hardening models have been proposed by Azevedo [38]. Combined with TEM analysis regarding the number density and size of dislocation loops in the CLAM steel irradiated with single-( $\left.\mathrm{He}^{+}\right)$and sequential-( $\mathrm{He}^{+}$plus $\mathrm{H}^{+}$subsequently), the magnitude of irradiation-induced hardening was well expounded in terms of a dispersed barrier hardening model [39]. The model can be written as

$$
\Delta \sigma_{\mathrm{y}}=M \cdot \alpha \cdot \mu \cdot b(N d)^{0.5}
$$

where $\Delta \sigma_{\mathrm{y}}$ is the increment in yield strength, $M$ is the Taylor factor, $\alpha$ is the strength of barrier, $\mu$ is the shear modulus, $b$ is the magnitude of the Burger's vector for moving dislocations, $N$ is the number density of obstacles, and $d$ is the obstacle diameter [14]. Therefore, the number density and size of dislocation loops would determine the magnitude of irradiation hardening in the irradiated CLAM steel. In the case of P92 steel, the product of density and size of dislocation loops in the P92 steel irradiated at $400{ }^{\circ} \mathrm{C}$ was larger than that irradiated at $200{ }^{\circ} \mathrm{C}$ according to a dispersed barrier hardening model. Meanwhile, a smaller magnitude of irradiation-induced hardening was observed in the P92 steel irradiated at $400{ }^{\circ} \mathrm{C}$. Therefore, point defects and other defect clusters should be taken into consideration to understand the magnitude of irradiation-induced hardening in P92 steel irradiated at 200 and $400{ }^{\circ} \mathrm{C}$ with the exception 
of dislocation loops. It was suggested that irradiation-induced defects with a small size contributing to irradiation hardening could not be observed due to the resolution limit of TEM [40]. It can be speculated that irradiation hardening in P92 steel irradiated at $200{ }^{\circ} \mathrm{C}$ is attributed to the production of both dislocation loops and other fine irradiation defects. The annihilation between vacancy and interstitial atoms occurs during irradiation independent of irradiation temperature, while the annihilation will become more obvious with increasing irradiation temperature [33]. Thus, it can be inferred that defect clusters decreased in the irradiated P92 steel due to the occurrence of annihilation of vacancy and interstitial atoms partly at $400{ }^{\circ} \mathrm{C}$. The annihilation of irradiation defects during irradiation at $400{ }^{\circ} \mathrm{C}$ is the main factor leading to slight hardening in the irradiated P92 steel at this temperature.
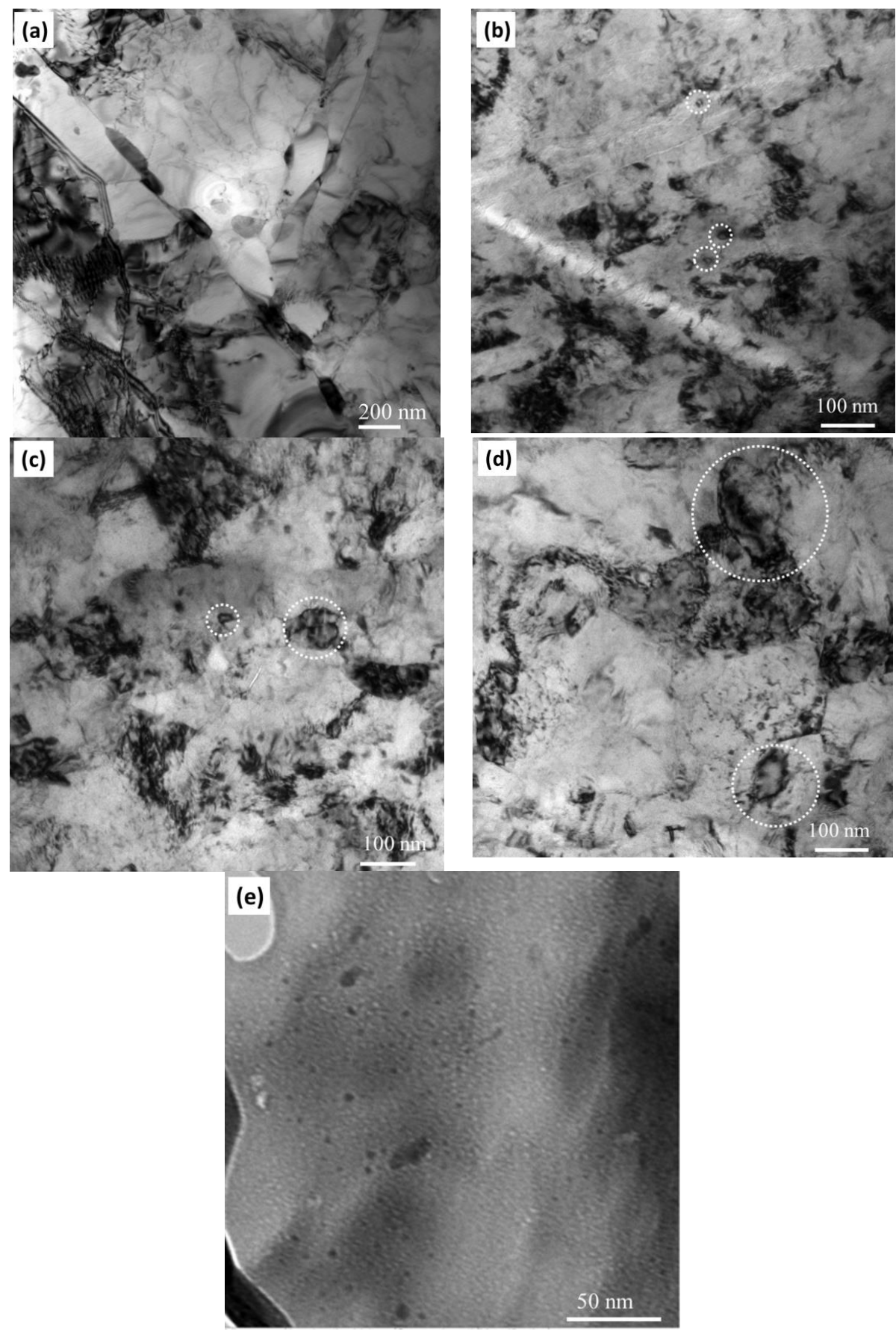

Figure 4. TEM micrographs of P92 steel (a) before and after Ar ion irradiation to $10 \mathrm{dpa}$ at (b) $200{ }^{\circ} \mathrm{C}$, (c) $400{ }^{\circ} \mathrm{C}$, and (d,e) $700{ }^{\circ} \mathrm{C}$. 
With the increasing of irradiation temperature up to $700{ }^{\circ} \mathrm{C}$, significant irradiation hardening was observed in the irradiated P92 steel. At high temperatures, irradiation-induced defect clusters will become unstable, meanwhile the absorption of point defects to dislocations makes the hardening decrease. However, fine bubbles were observed to homogeneously distribute in the sample irradiated at $700{ }^{\circ} \mathrm{C}$, as shown in Figure $4 \mathrm{e}$. It has been confirmed that high-density helium bubbles could act as obstacles to dislocation motion leading to hardening [41,42]. Therefore, the irradiation-induced hardening in the irradiated $\mathrm{P92}$ steel at $700{ }^{\circ} \mathrm{C}$ can result from the formation of uniformly distributed Ar bubbles with a high number density and fine size. These uniformly distributed Ar bubbles can be considered as a stronger barrier to the motion of dislocation resulting in the hardening in the irradiated P92 steel. In addition, it can be inferred that the hardness increase caused by the formation of Ar bubbles is stronger than the hardness decrease resulting from annihilation of other irradiation defects. The formation of cavities at a higher irradiation temperatures was also observed in other studies. It has been reported that cavities with a high number density were observed in Fe-Cr-Mn alloy irradiated with Ar ions at $450{ }^{\circ} \mathrm{C}$ [43]. Recently, irradiation-induced cavity was found in P92 steel irradiated with Ar ions at $550{ }^{\circ} \mathrm{C}$ to $7 \mathrm{dpa}$, while no cavity was observed in the steel irradiated at temperatures below $550{ }^{\circ} \mathrm{C}$ up to a high dose of 34.5 dpa $[19,20]$. In the present study, Ar bubbles contributing to hardening were also merely observed in the steel irradiated at $700{ }^{\circ} \mathrm{C}$, which might be due to a sufficient mobility for Ar atoms to nucleate and form Ar bubbles at the high irradiation temperature. Thus, the irradiation-induced hardening in the P92 steel occurred at $700{ }^{\circ} \mathrm{C}$ is mainly attributed to the production of these high-density and fine Ar bubbles.

\section{Conclusions}

Irradiation-induced hardening of P92 steel irradiated with Ar ions has been investigated with nanoindentation tests and microstructure analyses. Hardening behavior occurs in the steel after Ar ion irradiation at temperatures of 200,400 , and $700{ }^{\circ} \mathrm{C}$ to $10 \mathrm{dpa}$. P92 steel exhibits significant hardening at 200 and $700{ }^{\circ} \mathrm{C}$, and slight hardening at $400{ }^{\circ} \mathrm{C}$. Irradiation hardening in steel is sensitive to irradiation temperatures. Dominant irradiation-induced defects are different at different temperatures. Irradiation hardening observed in the $\mathrm{P} 92$ steel irradiated at $200{ }^{\circ} \mathrm{C}$ is considered to be attributed to the production of defects cluster and dislocation loops. Significant hardening in the P92 steel irradiated at $700{ }^{\circ} \mathrm{C}$ is due to the generation of high-density and fine Ar bubbles. The annihilation of irradiation defects during irradiation at $400{ }^{\circ} \mathrm{C}$ is a major factor leading to slight hardening in the irradiated steel.

Acknowledgments: This investigation was supported by the Key Program of National Natural Science Foundation of China (51034011), ITER-National Magnetic Confinement Fusion Program (2011GB113001), and Shanghai Pujiang Program. The authors thank Bo Ji and Aidang Shan from Shanghai Jiao Tong University for polishing steel samples and providing heat-treated steel plates, respectively.

Author Contributions: Qingshan Li analyzed the experimental data and completed this paper. Yinzhong Shen designed this experiment and revised the manuscript. Jun Zhu performed the nanoindentation experiments. Xi Huang and Zhongxia Shang helped to complete the microstructure analysis.

Conflicts of Interest: The authors declare no conflict of interest.

\section{References}

1. Kimura, A.; Cho, H.S.; Toda, N.; Kasada, R.; Yutani, K.; Kishimoto, H.; Iwata, N.; Ukai, S.; Fujiwara, M. High burn up fuel cladding materials R \& D for advanced nuclear systems nano-sized oxide dispersion strengthening steels. J. Nucl. Sci. Technol. 2007, 44, 323-328. [CrossRef]

2. Boutard, J.L.; Alamo, A.; Lindau, R.; Rieth, M. Fissile core and Tritium-Breeding Blanket: Structural materials and their requirements. C. R. Phys. 2008, 9, 287-302. [CrossRef]

3. Murty, K.L.; Charit, I. Structural materials for Gen-IV nuclear reactors: Challenges and opportunities. J. Nucl. Mater. 2008, 383, 189-195. [CrossRef]

4. Calder, A.F.; Bacon, D.J.; Barashev, A.V.; Osetsky, Y.N. On the origin of large interstitial clusters in displacement cascades. Philos. Mag. 2010, 90, 863-884. [CrossRef] 
5. Bloom, E.E.; Zinkle, S.J.; Wiffen, F.W. Materials to deliver the promise of fusion power-Progress and challenges. J. Nucl. Mater. 2004, 329-333, 12-19. [CrossRef]

6. Matijasevic, M.; Van Renterghem, W.; Almazouzi, A. Characterization of irradiated single crystals of Fe and Fe-15Cr. Acta Mater. 2009, 57, 1577-1585. [CrossRef]

7. Kohyama, A.; Katoh, Y.; Ando, M.; Jimbo, K. A new Multiple Beams-Material Interaction Research Facility for radiation damage studies in fusion materials. Fusion Eng. Des. 2000, 51-52, 789-795. [CrossRef]

8. Was, G.S. Fundamentals of Radiation Materials Science; Springer: New York, NY, USA, 2007; pp. 545-565, ISBN 978-3-540-49471-3.

9. Zhang, C.H.; Jang, J.; Kim, M.C.; Cho, H.D.; Yang, Y.; Sun, Y.M. Void swelling in a 9Cr ferritic/martensitic steel irradiated with energetic Ne-ions at elevated temperatures. J. Nucl. Mater. 2008, 375, 185-191. [CrossRef]

10. Topbasi, C.; Kaoumi, D.; Motta, A.T.; Kirk, M.A. Microstructural evolution in NF616 (P92) and Fe-9Cr-0.1C model alloy under heavy ion irradiation. J. Nucl. Mater. 2015, 466, 179-186. [CrossRef]

11. Topbasi, C.; Motta, A.T.; Kirk, M.A. In situ study of heavy ion induced radiation damage in NF616 (P92) alloy. J. Nucl. Mater. 2012, 425, 48-53. [CrossRef]

12. Zhao, F.; Qiao, J.; Huang, Y.; Wan, F.; Ohnuki, S. Effect of irradiation temperature on void swelling of China Low Activation Martensitic steel (CLAM). Mater. Charact. 2008, 59, 344-347. [CrossRef]

13. Peng, L.; Huang, Q.; Ohnuki, S.; Yu, C. Swelling of CLAM steel irradiated by electron/helium to 17.5 dpa with 10 appm He/dpa. Fusion Eng. Des. 2011, 86, 2624-2626. [CrossRef]

14. Gai, X.; Lazauskas, T.; Smith, R.; Kenny, S.D. Helium bubbles in bcc Fe and their interactions with irradiation. J. Nucl. Mater. 2015, 464, 382-390. [CrossRef]

15. Fischer-Cripps, A.C. Nanoindentation, 2nd ed.; Springer: New York, NY, USA, 2004; pp. 147-161, ISBN 978-1-4419-9871-2.

16. Takayama, Y.; Kasada, R.; Sakamoto, Y.; Yabuuchi, K.; Kimura, A.; Ando, M.; Hamaguchi, D.; Tanigawa, H. Nanoindentation hardness and its extrapolation to bulk-equivalent hardness of F82H steels after single- and dual-ion beam irradiation. J. Nucl. Mater. 2013, 442, S23-S27. [CrossRef]

17. Kasada, R.; Konishi, S.; Yabuuchi, K.; Nogami, S.; Ando, M.; Hamaguchi, D.; Tanigawa, H. Depth-dependent nanoindentation hardness of reduced-activation ferritic steels after $\mathrm{MeV}$ Fe-ion irradiation. Fusion Eng. Des. 2014, 89, 1637-1641. [CrossRef]

18. Klueh, R.L.; Nelson, A.T. Ferritic/martensitic steels for next-generation reactors. J. Nucl. Mater. 2007, 371, 37-52. [CrossRef]

19. Jin, S.X.; Guo, L.P.; Yang, Z.; Fu, D.J.; Liu, C.S.; Tang, R.; Liu, F.H.; Qiao, Y.X.; Zhang, H.D. Microstructural evolution of $\mathrm{P} 92$ ferritic/martensitic steel under argon ion irradiation. Mater. Charact. 2011, 62, 136-142. [CrossRef]

20. Jin, S.; Guo, L.; Li, T.; Chen, J.; Yang, Z.; Luo, F.; Tang, R.; Qiao, Y.; Liu, F. Microstructural evolution of P92 ferritic/martensitic steel under $\mathrm{Ar}^{+}$ion irradiation at elevated temperature. Mater. Charact. 2012, 68, 63-70. [CrossRef]

21. Huang, Y.; Wharry, J.P.; Jiao, Z.; Parish, C.M.; Ukai, S.; Allen, T.R. Microstructural evolution in proton irradiated NF616 at $773 \mathrm{~K}$ to 3 dpa. J. Nucl. Mater. 2013, 442, S800-S804. [CrossRef]

22. Huang, X.; Shen, Y.; Zhu, J. Influence of Ar-ions irradiation on the oxidation behavior of ferritic-martensitic steel P92 in supercritical water. J. Nucl. Mater. 2015, 457, 18-28. [CrossRef]

23. Ziegler, J.F. SRIM-2008 Program. 2008. Available online: http:/ / www.srim.org (accessed on 12 January 2017).

24. Oliver, W.C.; Pharr, G.M. An improved technique for determining hardness and elastic modulus using load and displacement sensing indentation experiments. J. Mater. Res. 1992, 7, 1564-1583. [CrossRef]

25. Nix, W.D.; Gao, H. Indentation size effects in crystalline materials: A law for strain gradient plasticity. J. Mech. Phys. Solids 1998, 46, 411-425. [CrossRef]

26. Kasada, R.; Takayama, Y.; Yabuuchi, K.; Kimura, A. A new approach to evaluate irradiation hardening of ion-irradiated ferritic alloys by nano-indentation techniques. Fusion Eng. Des. 2011, 86, 2658-2661. [CrossRef]

27. Hardie, C.D.; Roberts, S.G. Nanoindentation of model Fe-Cr alloys with self-ion irradiation. J. Nucl. Mater. 2013, 433, 174-179. [CrossRef]

28. Suresh, S.; Giannakopoulos, A.E. A new method for estimating residual stresses by instrumented sharp indentation. Acta Mater. 1998, 46, 5755-5767. [CrossRef] 
29. Janssen, G.C.A.M.; Abdalla, M.M.; van Keulen, F.; Pujada, B.R.; van Venrooy, B. Celebrating the 100th anniversary of the Stoney equation for film stress: Developments from polycrystalline steel strips to single crystal silicon wafers. Thin Solid Films 2009, 517, 1858-1867. [CrossRef]

30. Ghidelli, M.; Sebastiani, M.; Collet, C.; Guillemet, R. Determination of the elastic moduli and residual stresses of freestanding Au-TiW bilayer thin films by nanoindentation. Mater. Des. 2016, 106, 436-445. [CrossRef]

31. Allen, T.R.; Tan, L.; Gan, J.; Gupta, G.; Was, G.S.; Kenik, E.A.; Shutthanandan, S.; Thevuthasan, S. Microstructural development in advanced ferritic-martensitic steel HCM12A. J. Nucl. Mater. 2006, 351, 174-186. [CrossRef]

32. Kimura, A.; Morimura, T.; Narui, M.; Matsui, H. Irradiation hardening of reduced activation martensitic steels. J. Nucl. Mater. 1996, 233-237, 319-325. [CrossRef]

33. Xin, Y.; Ju, X.; Qiu, J.; Guo, L.; Chen, J.; Yang, Z.; Zhang, P.; Cao, X.; Wang, B. Vacancy-type defects and hardness of helium implanted CLAM steel studied by positron-annihilation spectroscopy and nano-indentation technique. Fusion Eng. Des. 2012, 87, 432-436. [CrossRef]

34. Tanigawa, H.; Klueh, R.L.; Hashimoto, N.; Sokolov, M.A. Hardening mechanisms of reduced activation ferritic/martensitic steels irradiated at $300{ }^{\circ} \mathrm{C}$. J. Nucl. Mater. 2009, 386-388, 231-235. [CrossRef]

35. Hu, W.; Luo, F.; Shen, Z.; Guo, L.; Zheng, Z.; Wen, Y.; Ren, Y. Hydrogen bubble formation and evolution in tungsten under different hydrogen irradiation conditions. Fusion Eng. Des. 2015, 90, 23-28. [CrossRef]

36. Shen, Y.; Zhu, J.; Huang, X. Ar ion irradiation hardening of high-Cr ferritic/martensitic steels at $700{ }^{\circ} \mathrm{C}$. Metals Mater. Int. 2016, 22, 181-186. [CrossRef]

37. Anderoglu, O.; Byun, T.S.; Toloczko, M.; Maloy, S.A. Mechanical performance of ferritic martensitic steels for high dose applications in advanced nuclear reactors. Metall. Mater. Trans. A 2013, 44, 70-83. [CrossRef]

38. Azevedo, C.R.F. A review on neutron-irradiation-induced hardening of metallic components. Eng. Fail. Anal. 2011, 18, 1921-1942. [CrossRef]

39. Fu, Z.Y.; Liu, P.P.; Wan, F.P.; Zhan, Q. Helium and hydrogen irradiation induced hardening in CLAM steel. Fusion Eng. Des. 2015, 91, 73-78. [CrossRef]

40. Lei, J.; Ding, H.; Shu, G.G.; Wan, Q.M. Study on the mechanical properties evolution of A508-3 steel under proton irradiation. Nucl. Instrum. Meth. Phys. Res. Sec. B Beam Interact. Mater. Atoms 2014, 338, 13-18. [CrossRef]

41. Osetsky, Y.N.; Stoller, R.E. Atomic-scale mechanisms of helium bubble hardening in iron. J. Nucl. Mater. 2015, 465, 448-454. [CrossRef]

42. Zhang, H.; Zhang, C.; Yang, Y.; Meng, Y.; Jang, J.; Kimura, A. Irradiation hardening of ODS ferritic steels under helium implantation and heavy-ion irradiation. J. Nucl. Mater. 2014, 455, 349-353. [CrossRef]

43. Zhang, C.; Chen, K.; Wang, Y.; Sun, J.; Hu, B.; Jin, Y.; Hou, M.; Liu, C.; Sun, Y.; Han, J.; et al. Microstructural changes in a low-activation Fe-Cr-Mn alloy irradiated with $92 \mathrm{MeV}$ Ar ions at $450{ }^{\circ} \mathrm{C}$. J. Nucl. Mater. 2000, 283-287, 259-262. [CrossRef]

(C) 2018 by the authors. Licensee MDPI, Basel, Switzerland. This article is an open access article distributed under the terms and conditions of the Creative Commons Attribution (CC BY) license (http:/ / creativecommons.org/licenses/by/4.0/). 